\title{
EDITORIAL
}

\section{In This Issue: Multifaceted Research}

Louise S. Acheson, MD, MS, Associate Editor

Jobn J. Frey III, MD, Associate Editor

Ann Fam Med 2009;7:482-483. doi:10.1370/afm.1070.

\section{ANTIBIOTICS WITHOUT A PRESCRIPTION}

I

n follow-up to a study showing the wide availability of antibiotics without prescription via the World

Wide Web, ${ }^{1}$ Mainous and colleagues found that a year-long multimedia campaign did not decrease the high incidence of acquiring antibiotics without a prescription among Latinos in a South Carolina community. ${ }^{2}$ Immigrants who had bought antibiotics without prescription in their home country were likely to continue this practice in the United States.

\section{ADDRESSING THE PRIMARY CARE WORKFORCE SHORTAGE}

The relationship between Federally Qualified Community Health Centers (FQHCs) and family medicine residency training programs should be better and more common than it is currently. FQHCs heavily depend on family doctors as providers of care, and family medicine has always had care of the underserved as one of its core missions. As Morris and Chen point out in their important analysis of some of the root causes of both successful and failed training/service partnerships, it comes down to people and their willingness to try new ideas and overcome the considerable regulatory obstacles that have grown up both for FQHCs and residency programs. ${ }^{3}$ At a time when demand for primary care is rising dramatically, however, particularly in urban and rural health professions shortage areas, the US government and Residency Review Committee should quickly answer the call for overlapping governing bodies, new lines of funding for communitybased programs with FQHCs, and the establishment of demonstration programs. Education and FQHCs are both a bit hidebound, and there is no better time than the present to try new ideas to find more compatible matches.

\section{MEASURING AND ENHANCING THE QUALITY OF PRIMARY CARE PRACTICE}

Halladay and colleagues report that responding to payer requests for quality and performance data can be costly for practices, with estimated costs of implementation ranging from less than $\$ 1,000$ to $\$ 11,100$ per practitioner, and maintenance from less than $\$ 100$ to $\$ 4,300$ per year. ${ }^{4}$ Electronic health record systems do not automatically lend themselves to performancereporting requirements, sometimes needing expensive changes to generate data for payers.

Providing pregnancy care and abortion within the medical home can increase patients' access to reproductive services. In this issue, Bennett et al show that family medicine residency faculty and residents, rigorously trained and supported by experienced clinicians, provided high-quality early abortion care in family practices. ${ }^{5}$ Medication abortion was often chosen.

Three multimethod studies in this issue shed light on practice team characteristics associated with preventive care and the process of changing roles to enhance care within primary care practices. Nowalk and colleagues found that widely varying immunization rates for older patients in urban settings are associated with such practice characteristics as time spent by physicians with patients and the use of standing orders. ${ }^{6}$ A practice-based research network study by Ferrer and colleagues showed that having medical assistants assess and refer patients to programs which promote health behavior change increased referrals but did not reduce health risk behaviors. ${ }^{7}$ They identified barriers, including medical assistants' need for more training and perhaps the need for a more concerted, sustained intervention. Gensichen and colleagues found that medical assistants who served as depression case managers in small primary care practices valued this new role, yet they experienced limited capacity for the increased workload. ${ }^{8}$

The fifth in a series of editorials on generalism explores change in health care through the lens of adaptive-renewal cycles. The authors call for efforts to nurture health care innovators as well as "strategies of connection, diversification, and focusing on the fundamental [to] strengthen resilience during the coming turbulent times." 


\section{ISSUES FOR CLINICAL RESEARCH}

Practice based research networks provide a laboratory for real-world clinical research. Galliher and colleagues measured the representativeness of family physicians voluntarily participating in the American Academy of Family Physicians' (AAFP) National Research Network and found that they were more similar than not to AAFP active members in clinical behaviors and related beliefs. ${ }^{10}$

A systematic review showed little evidence for the accuracy of monofilament testing to detect neuropathy in feet of patients with diabetes, even though such testing is advised by professional guidelines. ${ }^{11}$

Ewart and colleagues document that clinical trials frequently change their outcome measures from registration to publication, without explicitly discussing these changes in their reports. ${ }^{12}$

We hope that you will find this issue thought provoking. Perhaps you will marvel, as the editors do continually, at the multifaceted research in primary care and the coherence developing in this growing body of work.

Please join the discussion of articles at http://www. AnnFamMed.org.

To read or post commentaries in response to this article, see it online at http://www.annfammed.org/cgi/content/full/7/6/482.

\section{References}

1. Mainous AG III, Everett CJ, Post RE, Diaz VA, Hueston WJ. Availability of antibiotics for purchase without a prescription on the Internet. Ann Fam Med. 2009;7(5):431-435.
2. Mainous AG III, Diaz VA, Carnemolla M. A community intervention to decrease antibiotics used for self-medication among Latino adults. Ann Fam Med. 2009;7(6):520-526.

3. Morris CG, Chen FM. Training residents in community health centers: facilitators and barriers. Ann Fam Med. 2009;7(6):488-494.

4. Halladay JR, Stearns SC, Wroth T, et al. Cost to primary care practices of responding to payer requests for quality and performance data. Ann Fam Med. 2009;7(6):495-503.

5. Bennett IM, Baylson M, Kalkstein K, Gillespie G, Bellamy S, Fleischman J. Early abortion in family medicine: clinical outcomes. Ann Fam Med. 2009;7(6):527-533.

6. Zimmerman RK, Nowalk MP, Tabbarah M, Hart JA, Fox DE, Raymund $\mathrm{M}$. Understanding adult vaccination in urban, lower-socioeconomic settings: influence of physician and prevention systems. Ann Fam Med. 2009;7(6):534-541.

7. Ferrer RL, Mody-Bailey P, Jaén CR, Gott S, Araujo S. A medical assistant-based program to promote healthy behaviors in primary care. Ann Fam Med. 2009;7(6):504-512.

8. Gensichen J, Jaeger C, Peitz M, et al. Health care assistants in primary care depression management: role perception, burdening factors, and disease conception. Ann Fam Med. 2009;7(6):513-519.

9. Stange KC, Ferrer RL, Miller WL. Making sense of health care transformation as adaptive-renewal cycles. Ann Fam Med. 2009; 7(6):484-487.

10. Galliher JM, Bonham AJ, Dickinson LM, Staton EW, Pace WD. Representativeness of PBRN physician practice patterns and related beliefs: the case of the AAFP National Research Network. Ann Fam Med. 2009;7(6):547-554.

11. Dros J, Wewerinke A, Bindels PJ, van Weert HC. Accuracy of monofilament testing to diagnose peripheral neuropathy: a systematic review. Ann Fam Med. 2009;7(6):555-559.

12. Ewart R, Lausen H, Millian N. Undisclosed changes in outcomes in randomized controlled trials: an observational study. Ann Fam Med. 2009;7(6):542-546. 